\title{
Examen de inmigrantes ¿requisito para ser alemán?
}

\author{
LUNa Bolííar ManaUT \\ Deutsche Welle, Colonia
}

Conceder la nacionalidad es otorgar un pedazo de reconocimiento. Significa igualar los derechos a las obligaciones, porque al inmigrante siempre se le exige antes de que se le sea dado. Ha de pagar impuestos, ha de amoldarse a las reglas sociales, ha de aceptar y asimilar la cultura: todo ello a cambio de que se le permita vivir en una tierra que no es la suya, que no le pertenece porque el destino lo parió lejos. Pero ese beneplácito para habitar el país ajeno es momentáneo y frágil, ya que reserva a la tierra de los otros la posibilidad de expulsar al inmigrante cuando ellos, los otros, los que tienen los derechos, a los que les pertenece el suelo, lo consideren necesario. En el momento en que el inmigrante se hace nacional, ya nada lo distingue de los dueños. Los otros pierden el poder, por lo menos legal. El inmigrante es uno más. El Estado que no lo vio nacer está obligado a protegerlo.

Para muchos de los que nunca tuvieron o quisieron abandonar su tierra, el deseo de nacionalizarse en otro lugar es relacionado frecuentemente con un amor bucólico hacia la patria adoptiva. Esa es la primera razón por la que algunos alemanes no comprenden el revuelo generado cuando Volker Bouffier, el ministro del Interior del Estado alemán de Hesse, sacó a la palestra su idea, nada original, de introducir un examen sobre Alemania como requisito para la concesión de la nacionalidad germana. Si quieren ser alemanes, que conozcan primero el país, se decían. Y puesto que no se estaba hablando de permisos de residencia o de asilo, el mal moral no aparecía por ninguna parte.

La realidad es sin embargo, una vez más, muy diferente. Los que aspiran a la nacionalidad porque de corazón se sienten alemanes, son los menos. La mayoría busca abandonar el trapecio de plazos de estancia prorrogables, o no, con la intención de vivir una vida estable con un futuro que no pueda deparar tristes sorpresas, como la de tener que hacer el equipaje una vez pasado lo más duro: la llegada. Para la mayoría ser alemán no significa adorar las salchichas y vestir pantalones de cuero con tirantes en los ratos libres, sino disponer de un pasaporte con el que poder viajar sin trabas. Significa un mañana para ellos y para sus hijos, sin que funcionarios del Departamento de Extranjería les puedan «invitar» a abandonar el país.

El examen en sí no es más que un inofensivo formulario con cien preguntas que pondrían a prueba los conocimientos que el extranjero arrumba en su memoria sobre la cultura, la política, la historia, el deporte y otros temas varios relacionados con Alemania. Con un $50 \%$ de respuestas acertadas, a unas preguntas que siempre serían las mismas y en un tiempo aún por definir, el extranjero o inmigrante superaría el examen. Los estadounidenses poseen una prueba similar, que según los políticos de Hesse es aplicada con éxito, y a los holandeses la idea les entusiasmó tanto que se dieron más prisa que los alemanes por implantarla y ya ha entrado en vigor, con preguntas tan trascendentales como «el té, ¿se prepara con agua fría o con agua caliente?». A partir de ellas, los funcionarios podrán hacerse una idea sobre si ese extranjero posee o no la madurez necesaria para ser holandés.

$¿$ ¿ué puede tener de malo el conocimiento? Nada, por supuesto. Aprender siempre enriquece, y habla a favor del inmigrante el que se interese por el país en el que vive. Pero aquí la sabiduría abandona la curiosidad personal, el deseo de descubrir quiénes son esas personas con las que deseo compartir sociedad y cómo viven. El conocimiento se convierte, primero, en una obligación, y segundo, en una traba para alargar y dificultar un proceso, ya de sí largo y difícil.

¿Obligar a saber? Por qué no. ¿Pero por qué, si se permite también la pregunta, sólo se obliga a saber al extranjero? Si se da por supuesto que el alemán en sí, por el hecho de serlo y por el carácter que le imprime esta tierra en la que ha nacido, sería capaz de superar, siquiera por los pe- los, un examen en el que se le pregunta por el nombre de la última instancia judicial de Alemania, se incurre en un error que no se le escapa ni al ministro del Interior de Hesse. Pero el extranjero, si quiere ser alemán, ha de esforzarse, ha de ser mejor que los propios alemanes. Y los mismos que no sabrían ni escribir correctamente el nombre de su ciudad, absolutamente alemana, son los que con más fuerza reclaman que esos inmigrantes, antes de poder ser alemanes, aprendan algo sobre Alemania.

Como extranjera, a una le sobrecoge un sentimiento particular cuando es capaz de descubrir los errores gramaticales, no pocos, que los mismos alemanes infringen a su idioma. Como extranjera, saliendo de un examen de relaciones internacionales de la UNED con la que mato mis inexistentes ratos libres, comenté divertida en una ronda de germanos no precisamente cazurros de pueblo que me habían preguntado por Otto von Bismarck. Ninguno de ellos fue capaz de identificar al personaje. ¿Y es en este país donde se espera del inmigrante que honre a Alemania con sus conocimientos? Crítica que, que no se malinterprete, sería igual de válida en cualquier otro lugar. Porque a ver cuántos españoles saben quién era y qué hizo José Canalejas. Por nombrar a alguien.

El examen es, como dicen los Verdes alemanes, una forma de discriminación. Se crean dos varas de medir. Al extranjero se le debe exigir que respete las leyes y las normas de convivencia social. Que se acoja a los valores compartidos y que renuncie a esos elementos de su cultura que son incompatibles, claramente incompatibles, con la salvaguarda de los derechos humanos. Un examen no pude distinguir si el extranjero, cuando supere la prueba con el $50 \%$ de las respuestas acertadas, obligará o no a su hija menor de edad a casarse con un desconocido. $\mathrm{Y}$ a preguntas pretenciosas como "¿Qué le diría usted a alguien que mantuviese que el Holocausto es una invención?» nada obliga 
a contestar la verdad, además de que su mera presencia es un insulto para los muchos musulmanes, porque a ellos va dirigida, que no aprueban las tesis del presidente iraní.

No es que no existan mecanismos para controlar la concesión de nacionalidades y se haga necesario fijar algunas reglas. La cosa está más que reglamentada. El examen sería un requisito más, que no exime del cumplimiento de los restantes: llevar como mínimo ocho años viviendo en Alemania, hablar alemán y haber superado los cursos de idioma, jurar fidelidad al país, reconocer la constitución. Y para llevar ocho años viviendo en Alemania uno tiene que tener un trabajo, o estar casado con un alemán, y así cumplir de nuevo otra ristra de condiciones. A lo que hay que añadir que sobre el papel no aparecen los problemas surgidos en la práctica, no registrados en ningún sitio y que le pueden costar a uno la existencia.

Por ejemplo, hace unos meses el Tribunal Federal de Alemania, la última instancia judicial del país, sentenció a favor de un hombre que debía ser deportado. Su mujer alemana ya no podía protegerlo porque de ella estaba separado, y su hija se hubiera quedado sin padre si la Justicia no le hubiese dado a última hora la razón. Cuántos otros no habrán podido llegar hasta el Tribunal Federal de Alemania. O por ejemplo, las dificultades de las que se quejan los kosovares, a los que se les reclaman papeles que su desaparecido Estado ya no puede concederles.

Alemania tiene problemas más acuciantes que resolver, fruto de una política migratoria retrógrada e ineficaz. Durante años, los políticos de este país han cerrado los ojos ante la realidad, convenciéndose, como el fracasado que no quiere reconocer dónde metió la pata, de que éste no es un país receptor de inmigrantes. Nadie lo diría, con unas cifras que alcanzan los siete millones de extranjeros viviendo en Alemania.

Los que llegaron en los años 50 y 60 no eran inmigrantes, sino «trabajadores invi- tados», que no "fuerza de trabajo», como los llamaban los nazis. El Estado los «invitaba» a venir y a contribuir a forjar el «milagro alemán». Luego, los invitaba a marchar. Los españoles también acudimos a esta llamada y, para gloria de las instituciones alemanas, fueron los menos los que quisieron quedarse. Pero nosotros teníamos una patria que nos brindaba, por pequeña que fuera, una oportunidad. No para todos fue así. Muchos, sobre todo turcos, se quedaron. Sin dejar de ser nunca «invitados». Sus hijos nacieron en Alemania, y los hijos de sus hijos. Hasta tres o más generaciones de invitados, a los que nunca se les permitió ser alemanes porque, hasta hace muy poco, alemán sólo era aquel por cuyas venas corriese sangre alemana.

Este arcaísmo legal ha sido por fin eliminado y después de medio siglo, Alemania se pregunta, imagínense, si realmente es un país objeto de la emigración extranjera. Pero la semilla de la discordia no sólo ha echado raíces: es un árbol. Jóvenes sin identidad, que no son de aquí ni de allí, se aferran a tradiciones sin sentido con tal de disponer de algo que los diferencie de los que no quisieron aceptarles como iguales. Hablan alemán, nacieron en Alemania, se criaron en Alemania y del país de origen de sus padres no saben más que un par de datos sueltos escuchados en alguna conversación familiar. Sin embargo, siguen hablando con acento y refiriéndose a «ellos», los alemanes, y a «nosotros», los turcos, los iraníes, los italianos. Y es que formular la pregunta «y tú, ¿de dónde eres?», que para mí se convierte en un terrible agravio cuando la traduzco al español, es absolutamente normal en Alemania cuando uno se encuentra con personas de aspecto foráneo, por muy germanos que sean sus modales y muy perfecto que suene su alemán.

Hasta que no se acabe con el «nosotros y ellos», esta bomba de relojería no dejará de hacer tictac. Las energías deberían concentrarse en desactivar el artefacto y no en crear más potenciales kamikazes.

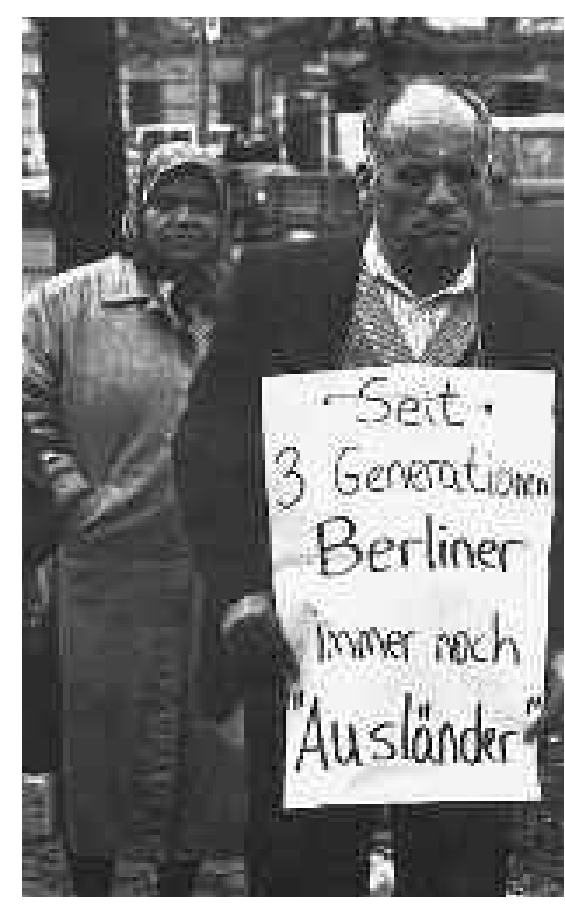

http://www.heimat-in-deutschland.de

\section{Referencias en la web:}

La «Staatsangehörigkeitsgesetz» al completo: http://www.gesetze-im-internet.de/bundesrecht/ rustag/gesamt.pdf

En el BIM (Ministerio de Interior) también hay mucha información:

http://www.bmi.bund.de

http://www.bmi.bund.de/cln_028/nn_122688/ Internet/Content/Themen/Staatsangehoerigkeit/Ein zelseiten/Erwerb_der_deutschen_Staatsbuergerschaft_durch_Eingbuergerung.html\#doc3331 20bodyText1

Y en el Auswärtiges Amt (Ministerio de Asuntos Exteriores):

http://www.auswaertiges-

amt.de/www/es/willkommen/auslaenderrecht/ zuwanderung_html

Aparte, así se lo imaginan en Hesse: http://www.hmdi.hessen.de/irj/HMdI_Internet?cid= 2f753b39dcfbacf6e78469557c917c90

Y tanto nosotros (Deutsche Welle), como el Süddeutsche Zeitung, hicimos un juego con algunas de las preguntas del test:

http://www2.dw-world.de/spanish/miniquiz/ 238/0.html

http://www.sueddeutsche.de/panorama/spiele/ perstest/74/72002/ 